\title{
Influence of Family History of Diabetes on Cardiac Autonomic Dysfunction of Adolescents
}

Carlos Alberto Alves Dias-Filho, ${ }^{\circledR}$ Nivaldo de Jesus Soares Jr., ${ }^{1 \oplus}$ Carlos José Dias, ${ }^{\circledR}$ Andressa Coelho Ferreira, ${ }^{1}$ Carlan da Silva Sena, ${ }^{1 \odot}$ Janaína de Oliveira Brito-Monzani, ${ }^{1 \odot}$ Rafael Martins Andrade, ${ }^{1 \oplus}$ Adeilson Serra Mendes

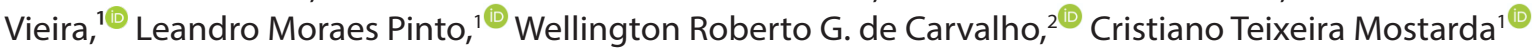

Universidade Federal do Maranhão,' São Luís, MA - Brazil

Universidade Federal de Uberlândia, ${ }^{2}$ Uberlândia, MG - Brazil

\section{Abstract}

Background: To evaluate cardiac autonomic modulation of adolescents with a family history of diabetic parents.

Objective: This study aims to evaluate the influence of a family history of diabetes on cardiac autonomic modulation.

Methods: This is an analytical and cross-sectional study on adolescents between 11 and 18 years of age, of both genders, who were divided into group with a family history of diabetes and a control group without a family history of diabetes. The study protocol consisted of the analysis of heart rate variability, blood pressure, anthropometric measurements, and body composition. Also, by using questionnaires, level of physical activity, sexual maturation, and sleep quality were evaluated. Normality of data distribution was tested using the Kolmogorov-Smirnov test. Then, statistical significance was evaluated using the Student's t-test, and the Hedges'g teste was used for calculation of the effect size. The level of significance adopted in the statistical analysis was $5 \%$.

Results: When the group of individuals with a family history of diabetes was compared with the control group, statistically significant differences were observed in the variables the standard deviation of the NN time series interval (SDNN) $(43.9 \pm 2.2$ vs. $53.5 \pm 2.6 \mathrm{~ms})$, the square root of the quadratic differences (RMSSD) $(41.9 \pm 3.3 \mathrm{vs}$. $52.4 \pm 3.2 \mathrm{~ms}$ ), standard deviation of beat-to-beat instantaneous variability (SD1) $(29.7 \pm 2.3 \mathrm{vs} .37 .1 \pm 2.3 \mathrm{~ms})$, longterm standard deviation of continuous RR intervals (SD2) (. $54.1 \pm 2.6 \mathrm{vs} .66 .66 \pm 3.5 \mathrm{~ms})$, and in low frequency (LF) $\left(496.0 \pm 49.5 \mathrm{vs} .728 \pm 71.6 \mathrm{~ms}^{2}\right)$ and high frequency $(\mathrm{HF})\left(1050.0 \pm 120.4 \mathrm{vs} .737 .4 \pm 98.5 \mathrm{~ms}^{2}\right)$ in the frequency domain.

Conclusions: Global autonomic modulation is decreased in adolescents with a family history of diabetes. We also observed a decrease in vagal activity in this group. So, sympathetic autonomic modulation is predominant in this population. (Int J Cardiovasc Sci. 2020; 33(4):360-367)

Keywords: Diabetes/heredity; Diabetes/Epidemiology; Adolescent; Body Weight; Body Mass Index, cardiac Autonomic System.

\section{Introduction}

Among the most common non-communicable chronic diseases worldwide, diabetes mellitus (DM) stands out because it affects more than 340 million people in the world. ${ }^{1}$ According to Irigoyen et al., ${ }^{2} \mathrm{DM}$ has reached epidemic proportions due to factors such as increased life expectancy, high prevalence of obesity and sedentary lifestyle. ${ }^{2}$

The main risk factors for the pathogenesis of DM are related to family history and lifestyle, such as impaired fasting blood glucose, reduced glucose tolerance, gestational diabetes, birth weight greater than $4 \mathrm{~kg}$, sedentary lifestyle, dyslipidemia (triglycerides 
$>250 \mathrm{mg} / \mathrm{dl}$ and $\mathrm{HDL}<35 \mathrm{mg} / \mathrm{dl}$ ), severe obesity, polycystic ovary syndrome, age $\geq 45$ years, moderate cardiovascular risk, and hypertension $(>140 / 90 \mathrm{mmHg}$ or antihypertensive use in adults). ${ }^{3}$ Thus, DM can be associated with different types of complications like autonomic dysfunctions in adult diabetic patients or their relatives with the disease. However, the prevalence of children and adolescents in pre-diabetic states or even with risk factors for type $2 \mathrm{DM}$ is still unknown. ${ }^{4}$

Additionally, one of the complications of DM is its relationship with autonomic imbalance associated and cardiovascular risk, due to its effects on the blood pressure regulatory system. 5,6 Thus, quantification of parasympathetic and sympathetic cardiac autonomic modulation is fundamental as indicator of cardiovascular function, ${ }^{7}$ because the autonomic nervous system plays a relevant role in the maintenance of cardiac homeostasis. Therefore, evaluation of heart rate variability (HRV) allows a sensitive and anticipated indication of the individual's health impairment. ${ }^{6}$

Studies show that a decrease in HRV promoted by a reduction in vagal activity has been associated with adverse events in normal individuals and patients with chronic diseases, and consequent increased risk of morbidity and mortality. ${ }^{8,9}$ Thus, this study aims to evaluate the influence of a family history of diabetes on cardiac autonomic modulation.

\section{Materials and Methods}

Sample

This study is part of a large Brazilian national project called Systemic Arterial Hypertension in Children and Adolescents (HASCA in Portuguese), which aims to monitor and study the development of hypertension in the early stages of life of the Brazilian population. HASCA is a national multicenter study based on nine Brazilian cities (Sao Luis, Pelotas, Sao Paulo, Aracaju, Porto Velho, Porto Alegre, Belo Horizonte, Rio de Janeiro, and Vitoria).

The sample consisted of 69 adolescent volunteers aged 11 to 18 years, selected by convenience, with 46 participants without a family history of diabetes (controls) and 23 with a family history of diabetes (FHD). Participants of this study were students from a state public school (Rio Anil Integrated Center - CINTRA) in São Luís, Brazil, which was randomly chosen by a simple draw among public schools.
To participate in the study, individuals should be present at all stages of data collection, which consisted of: (1) public call for the study and explanation about the project; (2) signature of the informed consent form by the parent or guardian of the child or adolescent, and signature of the informed consent form by the child or adolescent participating in the project; (3) assessment of anthropometric measurements and sexual maturation, administration of sleep quality questionnaires and physical activity level, and collection of capillary blood glucose and hemodynamic data. Subjects who were absent in any of the phases of the study, patients who reported to have any disease that may affect blood pressure (cardiovascular disease, chronic arterial hypertension, vasovagal syncope), and those using any medication to control blood pressure were excluded.

The study was approved by the research ethics committee of the Universidade Federal do Maranhão approval number 1378142 in accordance with the 466/12 resolution of the Brazilian National Health Council of the Ministry of Health.

\section{Body mass index}

For measurement of body weight, a Filizola ${ }^{\circledR}$ scale with a capacity of $150 \mathrm{~kg}$ and a sensitivity of $0.1 \mathrm{~kg}$, previously calibrated, was used. Volunteer were wearing light clothes and not wearing any accessories (e.g. bracelet, watches, ring). Height was measured using a Trena EST $23^{\circledR}$ compact stadiometer (2.10 $\mathrm{m}$ height), attached to the scale. The patient's head was positioned in the horizontal plane; the patient was barefoot, arms hanging loosely at their sides and heels straight, touching the stadiometer. ${ }^{10}$ From these measurements, the Body Mass Index (BMI) was calculated, obtained by the ratio of weight $(\mathrm{kg})$ by height squared, ${ }^{11}$ to assess the nutritional status of participants.

\section{Waist circumference}

Waist circumference (WC) was measured using an inelastic measuring tape at the edge of the iliac crest, with participant in expiration.12 WC was classified according to the criteria and cutoffs proposed by Fernández et al., ${ }^{13}$ 2004: < p10 (low) > p10 and < p75 (adequate); > p75 and $<$ p90 (high) > p90 (very high). ${ }^{13}$

\section{Pittsburgh Sleep Quality Index (PSQI)}

The Pittsburgh Scale, a self-administered questionnaire that assesses sleep quality over the past month, was applied. 
The PSQI identifies and separates people into the following groups - good sleep (overall score $\leq 4$ indicates), poor sleep (score $\geq 5$ ) sleep disorders (scores $\geq 10){ }^{14}$

\section{Heart rate variability}

HRV was recorded with a 12-lead electrocardiogram (WinCardio 6.1.1) and the $600 \mathrm{~Hz}$ electrocardiogram signal (Micromed Biotechnology Ltda) in the supine position for 10 minutes at rest, with spontaneous and normal respiratory rate (between 9 and 22 breaths per minute).

The indices were evaluated with Kubios VFC Analysis software, version 2.0 (Kubios, Finland).

\section{Time-domain variability}

RR interval time series were analyzed in 5-minute sections with a $50 \%$ overlap. Two competent observers analyzed the data using the Kubios $\mathrm{HRV}^{\circledR}$ software with automatic filter (Kuopio, Finland), the same used in the HRV analysis. Then, a multi-parameter HRV analysis was performed for the iRR time series. HRV parameters included mean normal-to-normal (NN) [mean NN (ms)] intervals, the standard deviation of the NN time series interval (SDNN), and the square root of the quadratic differences. NN intervals (RMSSD), the pNN50, as well as SD1 (standard deviation of beat-to-beat instantaneous variability) nonlinear analysis, SD2 (long-term standard deviation of continuous RR intervals; nu: normalized units; ms: milliseconds; $\mathrm{ms}^{2}$ : squared milliseconds) nonlinear analysis, and total variance.

\section{Frequency domain variability (Spectral Analysis)}

Frequency domain HRV measurements were characterized by the Fast Fourier Transform (FFT), in 5 -minute segments, $50 \%$ overlap, $4 \mathrm{hz}$ interpolation, divided into very low frequency (VLF 0 to $0.04 \mathrm{~Hz}$ ), low frequency (LF 0.04-0.15 Hz) and high-frequency (HF, 0.15-0.4 Hz) components. The sympathovagal balance was calculated by the ratio of LF to HF components and expressed in absolute values $\left(\mathrm{ms}^{2}\right)$ and normalized units (NU).

\section{Blood pressure}

For blood pressure measurements, two validated, automated blood pressure monitors were used (Omron ${ }^{\circledR}$ HEM-711 and OMROM ${ }^{\circledR}$ 905). The protocols used for analysis of blood pressure data followed the most recent guidelines of the Seventh Brazilian Guidelines on Hypertension $^{15}$ and the Fourth Report on the Diagnosis,
Evaluation, and Treatment of Hypertension in Children and Adolescents, ${ }^{15}$ including an age-appropriate cuff according to height percentiles. ${ }^{15}$

Volunteers were considered with altered blood pressure when the values reached the 95\% percentile, taking into account height, age and gender, according to the fourth report on Diagnosis, Assessment and Treatment of Hypertension in Children and Adolescents ${ }^{9}$ and Brazilian Hypertension Guidelines. ${ }^{16}$

\section{Assessment of physical activity}

Level and practice of physical activity were assessed using the International Physical Activity Questionnaire (IPAQ) - short version. ${ }^{17}$ The questions related to the activities performed in the week prior to the questionnaire administration.

\section{Sexual maturation}

The stage of sexual maturation was assessed according to the criteria proposed by Tanner. ${ }^{18}$ Girls and boys were assessed by female evaluators and male evaluators, respectively, to avoid embarrassment.

\section{Blood glucose test}

Postprandial capillary blood glucose was measured using a calibrated portable glucometer (ON CALL PLUS), using their respective reagent strips to ensure their accuracy.

\section{Statistical analysis}

First, data were submitted to the Kolmogorov-Smirnov normality test. Then, the one-tailed, unpaired Student's t-test was used to analyze differences between the groups (FHD and Control). The size effect was calculated according to the Hedges'g method in which indices greater than 0.8 showed high clinical relevance. The level of significance adopted in the statistical analyses was $5 \%$. Data are shown as mean and standard deviation. Statistica ${ }^{\circledR} 5.0$ software was used for data analysis.

\section{Results}

The anthropometric and metabolic variables of the Control group and the FHD group are presented in Table 1. When compared with the Control group, the FHD group showed no statistically significant differences in body composition, age, height, weight, systolic blood pressure (SBP), diastolic blood pressure 
(DBP), waist circumference (WC), body fat percentage, body mass index, glycemia, sexual maturation index or sleep quality. Nonetheless, although WC was not statistically different between the groups, the size of the effect showed high clinical relevance when comparing the groups.

The HRV of the Control and the FHD groups are shown in Figure 1 and Table 2. No statistically significant differences were observed between the groups in the time domain variables RR average, pNN50 (\%) and total variance $\left(\mathrm{ms}^{2}\right)$, but differences were observed in SDNN, RMSSD, SD1, and SD2. The variables LF $\left(\mathrm{ms}^{2}\right)$ and HF $\left(\mathrm{ms}^{2}\right)$, in the frequency domain, also showed statistical differences. The other frequency domain variables in normalized units - LF (nu) and HF (nu) - and the LF/HF balance did not show significant differences. However, it is important to highlight that both LF/HF and the total variance $\left(\mathrm{ms}^{2}\right)$ showed to have a significant clinical impact when the effect size was evaluated.

\section{Discussion}

The main finding of this study was a decrease in vagal activity in children of diabetic parents before the manifestation of any change in glycemia, suggesting an impairment in cardiac autonomic modulation.
These results can be observed in the HRV of the participants, which does not corroborate the study by Rocha et al., ${ }^{8}$ which compared the autonomic function of individuals aged 18 to 49 years, with and without a family history of type 2 DM (DM2) in the absence of glucose intolerance. In this study, the authors observed differences in BMI, serum lipids, leptin, and C-reactive protein, in addition to similar autonomic parameters between the groups. In contrast, our results indicated earlier changes in HRV, which, in turn, corroborate the study by Iellamo et al., ${ }^{19}$ which showed that these changes occur primarily in individuals with diabetic parents.

Anthropometric indices, sexual maturation, Pittsburgh's sleep quality, SBP, DBP, blood glucose and physical activity level were not significantly different between the groups, showing that they were not determining factors to changes in the HRV. However, WC showed a high effect, a result that corroborates studies that relate abdominal fat accumulation with the increase of WC as an important risk factor for the development of DM2. ${ }^{20,21}$

In addition, it was possible to notice a reduction in HRV in individuals with a family history of diabetes, with worse cardiac autonomic modulation, resulting in greater sympathetic activity. ${ }^{22-24}$ This suggests that altered autonomic function would precede the onset of glycemic dysfunction, which corroborates the study by

Table 1 - Body composition of adolescents without a family history of diabetes (controls) and adolescents with a family history of diabetes (FHD)

\begin{tabular}{|c|c|c|c|c|}
\hline & Controls $(n=46)$ & FHD $(n=23)$ & $p$ & Effect size \\
\hline Age (years) & $16.41 \pm 1.33$ & $16.16 \pm 1.8$ & 0.52 & 0.16 \\
\hline Height (cm) & $163.3 \pm 1.173$ & $159.9 \pm 1.717$ & 0.10 & 2.47 \\
\hline Weight (kg) & $57.00 \pm 1.617$ & $53.97 \pm 2.085$ & 0.26 & 1.69 \\
\hline Waist circumference (cm) & $72.4 \pm 1.160$ & $70.29 \pm 1.462$ & 0.27 & 1.66 \\
\hline Body fat (\%) & $26.79 \pm 1.374$ & $26.07 \pm 1.465$ & 0.74 & 0.51 \\
\hline Body mass index $\left(\mathrm{kg} / \mathrm{m}^{2}\right)$ & $21.33 \pm 0.518$ & $21.02 \pm 0.612$ & 0.71 & 0.56 \\
\hline Systolic blood pressure (mmHg) & $112.45 \pm 2.332$ & $113.54 \pm 1.542$ & 0.75 & 0.51 \\
\hline Diastolic blood pressure (mmHg) & $65.16 \pm 1.102$ & $67.24 \pm 1.595$ & 0.28 & 1.61 \\
\hline Glycemia & $87.15 \pm 11.216$ & $83.31 \pm 10.725$ & 0.35 & 0.34 \\
\hline Sexual maturation index & $2.92 \pm 0.611$ & $2.89 \pm 0.311$ & 0.63 & 0.05 \\
\hline Pittsburgh & $1.54 \pm 0.658$ & $1.47 \pm 0.611$ & 0.65 & 0.10 \\
\hline IPAQ & $1.34 \pm 0.487$ & $1.62 \pm 0.517$ & 0.21 & 0.56 \\
\hline
\end{tabular}



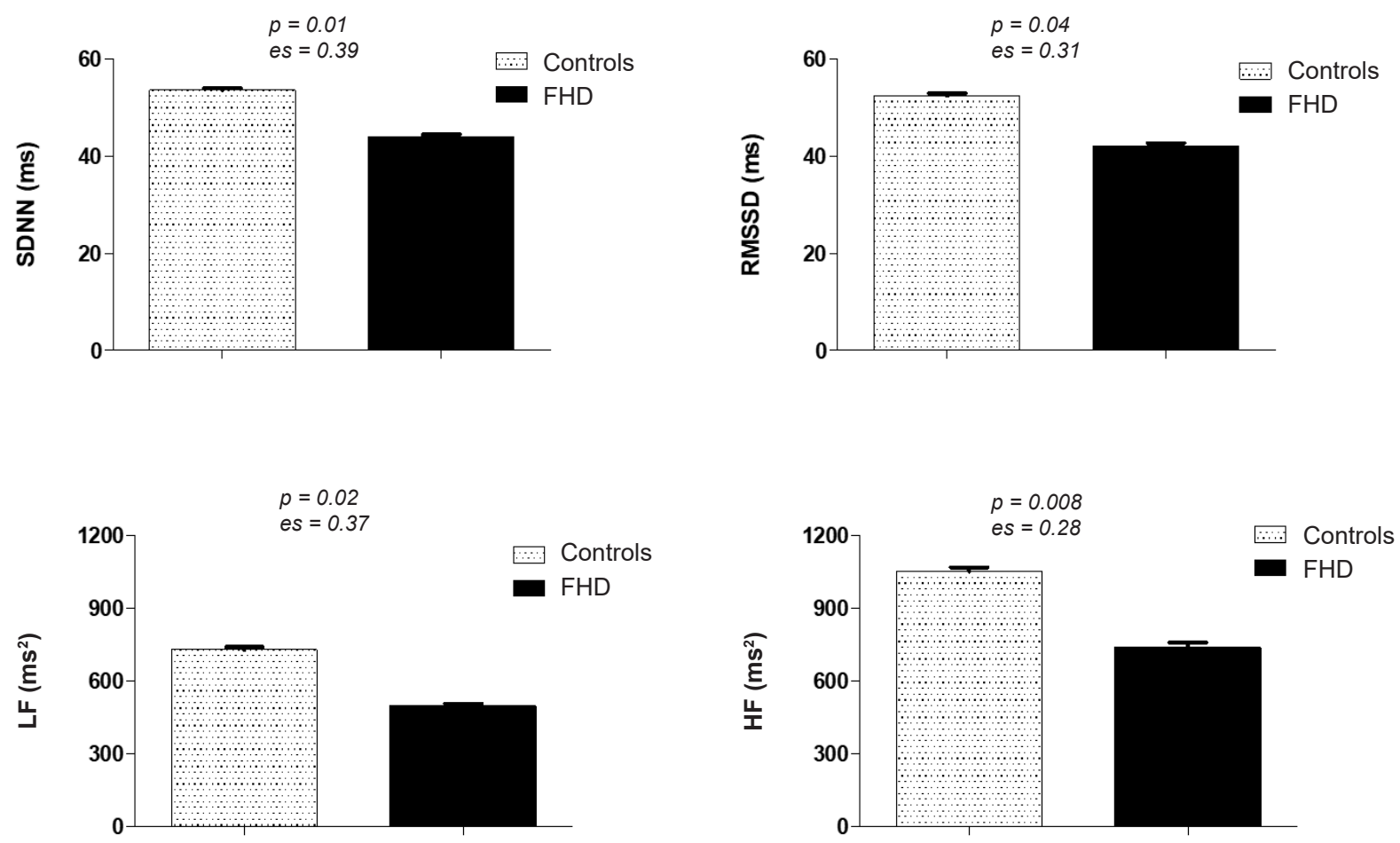

Figure 1 - Cardiac autonomic dysfunction in adolescents with and without a family history of type $\mathbf{2}$ diabetes mellitus. SDNN: standard deviation of all NN intervals; RMSSD: root mean square of successive differences of NN intervals (ms); LF: low frequency; HF: high frequency. One-tailed, unpaired Student's t-test. Control vs. family history of diabetes ( $p<0,05)$; es: effect size.

Table 2 - Variability analysis of heart rate in adolescents without a family history of diabetes (controls) and adolescents with a family history of diabetes (FHD)

Controls $(n=46)$

FHD (n = 23)

$p$

Effect size

Time domain

Total variance $\left(\mathrm{ms}^{2}\right)$

$1649.31 \pm 1154.67$

$1532.4 \pm 1154.60$

0.6614

0.10

Mean RR (ms)

$823.7 \pm 19.85$

$767.2 \pm 20.69$

0.0724

2.80

pNN50 (\%)

$32.67 \pm 3.083$

$24.00 \pm 3.327$

0.0784

Non-linear

$\mathrm{SD} 1(\mathrm{~ms})$

SD2 (ms)

Frequency domain

$\begin{array}{lc}\text { LF (nu) } & 45.17 \pm 2.465 \\ \text { HF (nu) } & 54.83 \pm 2.465 \\ \text { LF/HF } & 1.039 \pm 0.1156\end{array}$

$37.14 \pm 2.334$

$66.66 \pm 3.545$
$29.73+2.348$

$54.14 \pm 2.623$
0.0439

3.16

0.0186

3.82

pNN50: percentage of adjacent NN intervals differing by more than 50 milliseconds; SD1: standard deviation of the variation in the beat-to-beat interval; SD2: standard deviation of continuous or long-term variability of RR intervals; nu: normalized units; ms: milliseconds; ms²: milliseconds squared;

LF: low-frequency component; HF: high-frequency component; data presented as mean \pm standard error; Student's $t$-test. Controls vs FHD ( $p<0.05$ ).

The size effect was calculated according to the Hedges'g method. 
Fiorentini et al., ${ }^{25}$ with 75 individuals with a mean age of 47.71 years, divided into a group with a family history of DM2 and insulin resistance, a group of descendants with a family history without insulin resistance and a control group. The authors identified that changes related to the reduction in autonomic system function were associated with a family history of diabetes. ${ }^{25}$

The results in this study showed changes in cardiac autonomic modulation suggestive of lower vagal activity, which was also noted in the study by Kardelen et $a .^{26}$ in children with an average age of 12 years and insulin dependence.

The time-domain RMSSD $\left(\mathrm{ms}^{2}\right)$ and SDNN variables confirmed a lower cardiac autonomic modulation in children of diabetic parents found in the analysis of adjacent RR intervals, ${ }^{27}$ reflecting a decrease in vagal activity. ${ }^{28}$ Therefore, a significant decrease in RMSSD and SDNN is indicative of a reduction in vagal tone and greater modulation of the cardiac sympathetic autonomic nervous system as shown in adolescents in the family history of diabetes group, corroborating previous studies. ${ }^{26,29,30}$

Analysis of the frequency domain revealed that HF $\left(\mathrm{ms}^{2}\right)$ and LF $\left(\mathrm{ms}^{2}\right)$ indices are lower in children of diabetics, corroborating the studies by Chen et al. ${ }^{31}$ and Malik et al., ${ }^{32}$ including DM2 children aged from eight to 12 years, showing a decrease in the LF $\left(\mathrm{ms}^{2}\right), \mathrm{HF}$ $\left(\mathrm{ms}^{2}\right)$ components, as well as in total variance. Although our study did not show significant differences in total variance, this parameter showed a high effect size, indicating important clinical representativeness.

The LF/HF ratio, a marker of autonomic imbalance, was lower in children with parents with DM2. This is different from the study by Fiorentini et al., ${ }^{25}$ which identified changes in $\mathrm{LF} / \mathrm{HF}$ ratio indicating lower vagal activity in 70 Caucasian individuals, mean age of 47 years, descended from parents with DM2. The failure to identify autonomic imbalance in the present study may be related to the age range of the groups in our study, since autonomic nervous system disorders in insulinresistant patients are closely related to longer exposure to the disorder. ${ }^{33,34}$ However, it is important to emphasize that the LF/HF balance showed a strong effect, supporting it as an important marker of clinical changes in cardiac autonomic modulation in adolescents with a family history of diabetes.

The SD1 and SD2 values indicated a lower vagal activity in the FHD group, which corroborates the findings of Kaminski et al. ${ }^{35}$ who evaluated the sympathovagal activity in adult individuals. However, their sample comprised individuals aged 11 to 18 years incomplete, which makes the findings important evidence for a better understanding and early identification of an association of cardiac autonomic dysfunction with a genetic factor in the etiology of this condition.

First-degree relatives of individuals with DM2 are known to have two to six times greater risk of developing the disease compared with individuals with no family history of diabetes. ${ }^{36}$ In this case, the genetic component is a determining factor, where the possibility of individuals with a family history of diabetes is five to ten times higher for the development of the disease than the general population. ${ }^{37}$

In terms of clinical and scientific relevance of the findings, some points need to be highlighted. First, in the studies reviewed, there was little scientific evidence, since HRV in adolescents with a family history of diabetes has been poorly studied and deserves further investigation. Our findings may be used in subclinical detection of autonomic dysfunctions, definition of the risk level, and in early diagnosis of hemodynamic and autonomic changes in offspring of individuals with DM. This would reduce overall mortality and the risk of the development of DM2, metabolic complications and other noncommunicable chronic diseases.

In interpreting these results, some limitations need to be considered. The study allowed verifying the existence of a family history of diabetes among participants, however, it was not possible to determine the type of DM in the parents; also, insulin and lipid levels of these individuals were not assessed, which could have provided relevant clinical information and should be explored in future studies.

\section{Conclusion}

Global autonomic modulation is decreased in adolescents with a family history of diabetes. It was also observed a vagal activity decrease (RMSSD and SD1 indices), indicating that a sympathetic modulation is predominant in this population.

\section{Acknowledgements}

Credit to FAPEMA and the CINTRA School Teaching Group for their support to the development of this research. 


\section{Author contributions}

Conception and design of the research: Mostarda CT. Acquisition of data: Dias-Filho CAA; SoaresJunior NJ; Sena CS; Andrade RM; Vieira ASM; Pinto LM. Analysis and interpretation of the data: Dias CJ; Ferreira AC. Statistical analysis: Carvalho WRG; Soares-Junior NJ. Writing of the manuscript: Dias-Filho CAA; Ferreira AC. Critical revision of the manuscript for intellectual content: Mostarda CT; Brito-Monzani JO; Dias CJ.

\section{Potential Conflict of Interest}

No potential conflict of interest relevant to this article was reported.

\section{Sources of Funding}

This study was funded by CNPq 442374/2014-3 and FAPEMA UNIVERSAL-00358/15-edict 40/2014.

\section{Study Association}

This study is not associated with any thesis or dissertation work.

\section{Ethics approval and consent to participate}

This study was approved by the Ethics Committee of the Universidade Federal do Maranhão under the protocol number 1.378.174/2015. All the procedures in this study were in accordance with the 1975 Helsinki Declaration, updated in 2013. Informed consent was obtained from all participants included in the study.

\section{References}

1. Danaei G, Finucane MM, Lu Y, Singh GM, Cowan MJ, Paciorek CJ, et al. National, regional, and global trends in fasting plasma glucose and diabetes prevalence since 1980: systematic analysis of health examination surveys and epidemiological studies with 370 country-years and 2. 7 million participants. Lancet. 2011;378(9785):31-40.

2. Irigoyen MC, De Angelis K, Schaan BDA, Fiorino P, Michelini LC. Exercício físico no diabetes melito associado à hipertensão arterial sistêmica. Rev Bras Hipertens.2003;10:109-16.

3. Inzucchi SE, Bergenstal RM, Buse JB, Diamant M, Ferrannini E, Nauck $\mathrm{M}$, et al. Management of hyperglycaemia in type 2 diabetes: a patientcentered approach. Position statement of the American Diabetes Association (ADA) and the European Association for the Study of Diabetes (EASD). Diabetologia. 2012;55(6):1577-96.

4. Parish RC, Todman S, Jain SK. Resting heart rate variability, inflammation, and insulin resistance in overweight and obese adolescents. Metabolic syndrome and related disorders. 2016;14(6):291-7.

5. Emdin M. Autonomic nervous system in diabetes. Ital Heart J Suppl.2001; 2(8):857-64.

6. Gardim CB, Oliveira BAPd, Bernardo AFB, Gomes RL, Pacagnelli FL, Lorençoni RMR, et al. Heart rate variability in children with type 1 diabetes mellitus. Rev Paul Pediatr. 2014;32(2):279-85.

7. Roy B, Ghatak S. Métodos não-lineares para avaliar mudanças na variabilidade da frequência cardíaca em pacientes com diabetes tipo 2. Arq Bras Cardiol. 2013;101(4):317-27.

8. Rocha NG, Neves FJd, Bousquet-Santos K, Silva BM, SOARES P, NÓBREGA A. História familiar de diabetes mellitus tipo 2 e modulação autonômica cardíaca. Rev SOCERJ. 2007;20(5):321-8.

9. Pal G, Adithan C, Amudharaj D, Dutta T, Pal P, Nandan P, et al. Assessment of sympathovagal imbalance by spectral analysis of hear rate variability in prehypertensive and hypertensive patients in Indian population. Clinical and Experimental Hypertension. 2011;33(7):478-83.

10. Varela AL, Quintans CC, Tranqueira APM, Gasparotto R, da Silva Isaac IA, Estrela RAM, et al. Programa de emagrecimento para mulheres obesas envolvendo variáveis nutricionais, psicológicas e exercício físico. RBONE-Revista Brasileira de Obesidade, Nutrição e Emagrecimento.2012;1(6):12-27.

11. World Health Organization. WHO. Child growth standards: length/ height-for-age, weight-for-age, weight-for-length, weight-forheight and body mass index-for-age: methods and development. Geneva;2006.

12. National Institutes of Health. NHLBI. Obesity Education Iniatiative The practical guide: identification, evaluation, and treatment of overweight and obesity in adults: Maryland (USA):NIH;2000. [Cited in 2018 Oct 12]. Available from: www.nhlbi.nihgov/guidelines/ obesity/prctgd_c.pdf

13. Fernández JR, Redden DT, Pietrobelli A, Allison DB. Waist circumference percentiles in nationally representative samples of African-American, European-American, and Mexican-American children and adolescents. J Pediatr. 2004;145:439-44.

14. Buysse DJ, Reynolds CF, Monk TH, Berman SR, Kupfer DJ. The Pittsburgh Sleep Quality Index: a new instrument for psychiatric practice and research. Psychiatry research. 1989;28(2):193-213.

15. Malachias M, Souza W, Plavnik F, Rodrigues C, Brandão A, Neves M: Sociedade Brasileira de Cardiologi. $7^{\mathrm{a}}$ Diretriz Brasileira de Hipertensão Arterial. Arq Bras Cardiol. 2016;107(3 Supl):1-103.

16. Lopes H, Silva H, Consolim-Colombo F, Barreto Filho J, Riccio G, Giorgi $\mathrm{D}$, et al. Autonomic abnormalities demonstrable in young normotensive subjects who are children of hypertensive parents. Braz J Med Biol Res. 2000;33(1):51-4

17. Matsudo S, Araújo T, Matsudo V, Andrade D, Andrade E, Oliveira LC, et al. Questionário internacional De atividade física (ipaq): estupo De validade e reprodutibilidade No Brasil. Rev Bras Ativ Fís Saúde. 2012;6(2):5-18.

18. Colli A, Coates V, Guimarães B, Coates V. Monitoração do crescimento e desenvolvimento físico. In: Coates V Medicina do adolescente São Paulo: Sarvier; 1993.p:51-65.

19. Iellamo F, Tesauro M, Rizza S, Aquilani S, Cardillo C, Iantorno M, et al. Concomitant impairment in endothelial function and neural cardiovascular regulation in offspring of type 2 diabetic subjects. Hypertension. 2006;48(3):418-23.

20. Picon PX, Leitão CB, Gerchman F, Azevedo MJd, Silveiro SP, Gross JL, et al. Medida da cintura e razão cintura/quadril e identificação de situações 
de risco cardiovascular: estudo multicêntrico em pacientes com diabetes melito tipo 2. Arq Bras Endocrinol Metab.2007;51(3):443-9.

21. Machado SP, Rodrigues DGC, Viana KDAL, de Carvalho Sampaio HA. Correlação entre o índice de massa corporal e indicadores antropométricos de obesidade abdominal em portadores de diabetes mellitus tipo 2. Rev Bras Promoç Saúde. 2013;25(4):512-20.

22. Freitas IMG, Miranda JA, Mira PAC, Lanna CMM, Lima JRP, Laterza MC. Cardiac autonomic dysfunction in obese normotensive children and adolescents. Rev Paul Pediatr. 2014;32(2):244-9.

23. Cayres SU, Vanderlei LCM, Rodrigues AM, Coelho e Silva MJ, Codogno JS, Barbosa MF, et al. Sports practice is related to parasympathetic activity in adolescents. Rev Paul Pediatr. 2015;33(2):174-80.

24. Li H, Kilpeläinen TO, Liu C, Zhu J, Liu Y, Hu C, et al. Association of genetic variation in FTO with risk of obesity and type 2 diabetes with data from 96,551 East and South Asians. Diabetologia. 2012;55(4):981-95.

25. Fiorentini A, Perciaccante A, Paris A, Serra P, Tubani L. Circadian rhythm of autonomic activity in non diabetic offsprings of type 2 diabetic patients. Cardiovasc Diabetol.2005 Oct 1;4:15.

26. Kardelen F, Akçurin G, Ertuğ H, Akcurin S, Bircan I. Heart rate variability and circadian variations in type 1 diabetes mellitus. Pediatr Diabetes. 2006;7(1):45-50.

27. Havlicekova Z, Tonhajzerová I, Jurko Jr A, Jesenak M, Durdik $\mathrm{P}$, Nosal S, et al. Cardiac autonomic control in adolescents with primary hypertension. Eur J Med Res. 2009;14(Suppl 4):101.

28. Kearney PM, Whelton M, Reynolds K, Muntner P, Whelton PK, He J. Global burden of hypertension: analysis of worldwide data. Lancet. 2005;365(9455):217-23.
29. Lucini D, Zuccotti G, Malacarne M, Scaramuzza A, Riboni S, Palombo C, et al. Early progression of the autonomic dysfunction observed in pediatric type 1 diabetes mellitus. Hypertension. 2009;54:987-94.

30. Javorka M, Javorkova J, Tonhajzerova I, Javorka K. Parasympathetic versus sympathetic control of the cardiovascular system in young patients with type 1 diabetes mellitus. Clin Physiol Funct Imaging. 2005;25(5):270-4.

31. Chen S-R, Lee Y-J, Chiu H-W, Jeng C. Impact of physical activity on heart rate variability in children with type 1 diabetes. Childs Nerv System. 2008;24(6):741-7.

32. Malik M, Bigger JT, Camm AJ, Kleiger RE, Malliani A, Moss AJ, et al. Heart rate variability: Standards of measurement, physiological interpretation, and clinical use. Eur Heart J. 1996;17(3):354-81.

33. Louzada SM, Vargas CR. Encefalopatia diabética e depressão: dano oxidativo no cérebro. Clin Biomed Res.2015;35(4):184-95.

34. Freitas IMG, Miranda JA, Mira PAC, Lanna CMM, Lima JRP, Laterza MC. Disfunção autonômica cardíaca em crianças e adolescentes obesos normotensos. Rev Paul Pediatr. 2014;32(2):244-9.

35. Kaminski DM, Schaan BDA, da Silva AMV, Soares PP, Plentz RDM Dall'Ago P. Inspiratory muscle weakness is associated with autonomic cardiovascular dysfunction in patients with type 2 diabetes mellitus. Clin Autonom Res. 2011;21(1):29-35.

36. Besseling J, Kastelein JJ, Defesche JC, Hutten BA, Hovingh GK Association between familial hypercholesterolemia and prevalence of type 2 diabetes mellitus. JAMA. 2015;313(10):1029-36.

37. Fox CS, Golden SH, Anderson C, Bray GA, Burke LE, De Boer IH, et al. Update on prevention of cardiovascular disease in adults with type 2 diabetes mellitus in light of recent evidence: a scientific statement from the American Heart Association and the American Diabetes Association. Circulation. 2015;132(8):691-718. 